\title{
Nest-site defence aggression during courtship does not predict nestling provisioning in male collared flycatchers
}

\author{
Eszter Szász ${ }^{1}$ [D $\cdot$ Gábor Markó $^{1,2} \cdot$ Gergely Hegyi $^{1} \cdot$ János Török $^{1}$ - László Zsolt Garamszegi ${ }^{3,4,5} \cdot$ Balázs Rosivall $^{1}$
}

Received: 5 April 2018 /Revised: 2 April 2019 / Accepted: 9 April 2019 / Published online: 27 April 2019

(C) The Author(s) 2019

\begin{abstract}
Individuals of many animal species show consistent differences in ecologically relevant behaviours, and these individual-specific behaviours can correlate with each other. In passerines, aggression during nest-site defence is one of those behaviours that have been steadily found to be repeatable within individuals. Furthermore, in several cases, aggression was related to some estimates of reproductive investment. Here, we studied the possibility that behaviour of males toward a male rival predicts the amount of their future parental care. This could be beneficial to the females, because during mate choice, they could use male aggressive behaviour as a cue for parental quality. We performed the study by video recording the nestling feeding activity of male collared flycatchers (Ficedula albicollis) that were assayed for aggression during the courtship period. The level of aggression was not related to feeding rate in males. Feeding rate of males differed between the study years, but it did not correlate with the feeding rate of their mates, neither was it related to the morphological traits of the parents. We may conclude that nest-site defence aggression of males does not predict their parental commitment. This may be surprising given that higher testosterone levels that may be expected in aggressive males often suppress parental care. However, among-individual variance in male testosterone profiles found to be decrease from the courtship to the parenting period in flycatchers, and this may explain why differences in territorial aggression did not manifest in differences in nestling provisioning. The correlation between behaviours that are expressed in distinct periods of the annual cycle of songbirds needs further investigation.
\end{abstract}

\section{Significance statement}

Male songbirds, when attracting mates, are often confronted with each other over nest-sites, and these male-male confrontations may be witnessed by females. If performance during territory defence predicts the quality of parental care that a male will provide for its nestlings, females could use defence behaviour as a cue for mate choice. To explore this possibility, we investigated the relationship between territorial aggression and nestling feeding activity of male collared flycatchers. We performed simulated territorial intrusions to measure the aggression of males and recorded their nestling feeding rate about a month later. We found that territorial aggression did not correlate with nestling feeding rate. This suggests that nest-site defence behaviour in the beginning of the breeding season does not carry information for females about what to expect from potential mates in terms of parental care.

Keywords Animal personality $\cdot$ Behavioural syndrome $\cdot$ Nestling feeding $\cdot$ Male-male competition $\cdot$ Mate choice $\cdot$ Parental care

Communicated by K. van Oers

Electronic supplementary material The online version of this article (https://doi.org/10.1007/s00265-019-2672-1) contains supplementary material, which is available to authorized users.

Eszter Szász

iciperezvon@gmail.com

Extended author information available on the last page of the article

\section{Introduction}

Parental provisioning is crucial for altricial birds because the young remain in the nest and depend on parental care for weeks after hatching. These species usually perform biparental care (Silver et al. 1985), and feeding by the male parent may significantly contribute to breeding success. Therefore, for the females, it may be vital to assess the parental skills of the potential mates already during the courtship period. Parental skills of the mate candidates may be indicated by 
their plumage, song and behavioural traits. Regarding plumage, numerous studies examined the correlation between colouration and feeding rate of the male parent. However, the overall support for a positive relationship between colour expression and feeding rate was not found to be convincing by a recent meta-analysis (Hegyi et al. 2015). The correlation between song traits and feeding rate of males has been rarely examined. The existing studies, however, seem to show that measures of song rate are related to feeding rate (Hofstad et al. 2002; Dolby et al. 2005), while measures of song complexity are not (Rinden et al. 2000; Hofstad et al. 2002; Dolby et al. 2005). The correlation between behavioural traits displayed during courtship and feeding rate of males, to our knowledge, has not yet been examined.

Several, non-exclusive theoretical frameworks suggest that such a relationship is likely to exist. Under the concept of phenotypic integration (Foster et al. 1992) or the existence of behavioural syndromes (Sih et al. 2004), we would expect a correlation between behaviours expressed during courtship and behaviours expressed during parental care. This is because functionally different behaviours could be governed by common genetic (Bakker 1986; van Oers et al. 2004) or physiological proximate mechanisms (Carere et al. 2003; Kralj-Fišer et al. 2007). In addition, if courtship and parental behaviour utilise the same limiting resources and are therefore traded off against each other (Stearns 1989), a correlation between these behaviours can be apparent. Based also on life-history (Stearns 1976) or pace-of-life (Ricklefs and Wikelski 2002; Réale et al. 2010) theory, parental investment is expected to correlate with behaviours of other social or ecological contexts. This is because expression of individual-specific behaviours could be coupled with the life-history of the individuals, which can be placed alongside a fast-slow continuum (Réale et al. 2010), and balanced according to the relative profit of current reproduction and residual reproductive value (Williams 1966).

A link between courtship and parental behaviour of males is also suggested indirectly by several empirical studies that found behavioural traits to play roles in mate choice (Otter and Ratcliffe 1996; Ophir and Galef 2003; Ophir et al. 2005; Kunc et al. 2006), differential allocation (Gwinner and Schwabl 2005; Grenna et al. 2014) or sex allocation (Ramsay et al. 2003; Szász et al. 2014).

One of the behaviours that seems to be likely to provide easily accessible information about future parental care is territorial aggression for the following reasons. First, aggressive disputes among males are open to be witnessed by females. In the laboratory, Japanese quail (Coturnix japonica) females were willing to observe male-male confrontations, evaluated the outcome and used the information in mate choice (Ophir and Galef 2003; Ophir et al. 2005) suggesting that such a mechanism could work in the wild too. Free-living nightingale (Luscinia megarhynchos) females indeed seem to make decision on the basis of male aggressiveness. In this species, male-male confrontations are resolved vocally, and those males that overlapped with playback songs more frequently were more likely to pair up later (Kunc et al. 2006). Second, territoriality and parenting are known to be conflicting activities due to the contrasting effects of testosterone (Silverin 1980; Wingfield et al. 1987), and testosterone profile considerably varies among individuals (Kempenaers et al. 2008).

We aimed to investigate whether the aggressive behaviour of males during the courtship period predicts parental behaviour in collared flycatchers (Ficedula albicollis) making it a valuable information source during mate choice or subsequent investment of the females. Apart from its general importance for evolutionary biology, the question is particularly interesting because aggressiveness of males during the courtship period against a conspecific intruder predicted the brood sex ratio that was produced later by their breeding partner (Szász et al. 2014). Specifically, mates of aggressive males produced female-biased broods, while those of less aggressive males produced male-biased broods (Szász et al. 2014). This result suggests that females assessed the aggressiveness of their mates and adjusted their reproductive decisions accordingly. Male offsprings in our study population are more sensitive to rearing conditions than females both in terms of nestling performance (Rosivall et al. 2010) and lifetime reproductive success (Szász et al. 2017). Therefore, a negative relationship between aggressiveness of males and their later parental contribution could explain the observed brood sex ratio adjustment.

To find out whether a behaviour expressed during courtship could predict the quality of future parental care, and to better understand the role of nest-site defence aggression in sex allocation in our study population, we tested the response of territorial males to simulated intrusion and examined nestling feeding by the same males a few weeks later. We expected that the aggressive response and the feeding activity of males would be negatively related to each other.

\section{Materials and methods}

\section{Study site and study species}

Our study was conducted in a nest-box breeding population of the collared flycatcher in the Pilis-Visegrádi Mountains, Hungary $\left(47^{\circ} 43^{\prime} \mathrm{N}, 19^{\circ} 01^{\prime} \mathrm{E}\right)$ over four breeding seasons (2013-2016). The study site is situated in a protected, middleaged, oak-dominated forest, and consists ca. of 800 nest-boxes mainly occupied by collared flycatchers.

The collared flycatcher is a small, migratory, insectivorous, primarily socially monogamous, hole-nesting passerine that breeds in deciduous forests in Europe. Males start to arrive at the breeding site in the middle of April, and immediately 
start to occupy and defend nest-boxes and their surroundings, while females arrive a bit later and search for a mate (Cramp and Perrins 1993). Females lay one clutch per breeding season (except for replacement clutches) containing on average 5-7 eggs (with a range of 3-9 eggs) that hatch roughly 12 days after clutch completion. Nestlings remain in the nest for 14 16 days. The female parent incubates alone, while both parents feed the nestlings.

\section{Behavioural assays}

Nest-site defence aggression of males was quantified during the courtship period by simulated intrusion tests. The observations were performed blindly with respect to the morphological traits of the males. The standardised test protocol has been described in detail earlier (Garamszegi et al. 2006). Males singing and displaying at a particular nest-box were confronted with a caged, alive, conspecific decoy male. Tests were observed from a hiding spot in the vegetation with binoculars, and latency to attack the decoy was measured with a stopwatch. Latency to attack was the time (in seconds) elapsed between the detection of the decoy and the first intention to attack the decoy. We considered the males to detect the decoy when they re-appeared on their territory. We recorded the first intention to attack when the males first touched the cage of the decoy from any side for more than $1 \mathrm{~s}$ and showed clear signs of fighting propensity (such as ruffling plumage, flicking wings, jumping and pecking). Earlier, we found that latency to attack is an accurate measure of aggression in our study population because it was repeatable within a breeding season and related to other variables describing nest-site defence aggression (such as number and duration of attacks; Garamszegi et al. 2006, 2015). Males that did not attack the decoy during the test were given a score of $301 \mathrm{~s} \mathrm{(5} \mathrm{min} \mathrm{is} \mathrm{the}$ maximal length of our test). All tests were done during the morning and early afternoon hours (test start time: 7:00 a.m.2:00 p.m.) when birds were the most active. All assayed males were assumed to be unfamiliar with the decoy males because they were trapped in non-adjacent study plots. We used decoy males randomly across tests and recorded their morphology and identity (i.e. ring number). Previously, we found an effect of the size of the wing patch of the decoy on the attack latency of the resident (Garamszegi et al. 2006). However, in the respective study years (2013-2016), neither the agestandardised size of the wing patch of the decoy (General Linear Model (GLM) with year and resident binary age as fixed factors: $n=155$ individuals, $F_{(1,149)}=0.783, p=$ 0.378 ) nor the identity of the decoy had significant effect on male territorial behaviour (log-likelihood ratio test between models containing and lacking decoy ID as random effect (resident binary age was a fixed effect): $\mathrm{AIC}=350.71$, 348.71 and $\log$-Lik $=-171.36,-171.36$, respectively; $\mathrm{Chi}^{2}$ $\sim 0, p \sim 1)$. Therefore, we did not consider decoy morphology and identity further.

After the behavioural test, we caught the assayed males in their nest-box with traditional spring traps for ringing and measurement. We measured tarsus length with a calliper to the nearest $0.1 \mathrm{~mm}$ and body mass with Pesola spring balance to the nearest $0.1 \mathrm{~g}$. We also measured the sizes of two white ornaments, the wing patch and the forehead patch, which are sexually selected and related to certain aspects of individual quality (Michl et al. 2002; Török et al. 2003; Garamszegi et al. 2004; Hegyi et al. 2007). To estimate wing patch size (hereafter WPS), we measured the length of the white bars on the 4th-8th primaries (Török et al. 2003) with a calliper to the nearest $0.1 \mathrm{~mm}$. To estimate forehead patch size (hereafter FPS), we measured the maximum height and width of the patch (Hegyi et al. 2002) with a calliper to the nearest $0.1 \mathrm{~mm}$. We also noted the age of the males based on the darkness of their remiges (brown indicates first-year and black indicates older males; Svensson 1992). After the measurements, we marked the assayed males on their belly feathers individually with ink for resighting, and released them.

\section{Video recordings}

We monitored all nesting attempts in our core study site to locate the assayed males. Resighting was done with binoculars while hiding in the vegetation either in the middle of the egg laying stage or shortly after hatching (when the hatchlings were 0-2 days old). In every year, we caught and identified approx. 40 males that were assayed for aggression (44, 39, 40 and 41 males in 2013, 2014, 2015 and 2016, respectively). We were subsequently able to follow the breeding performance of approx. half of these males in our study site $(16,21,25$ and 27 males in 2013, 2014, 2015 and 2016, respectively). Unfortunately, a large proportion of the initiated breeding attempts failed and could not be studied in every year due to complete or partial predation before or shortly after hatching $(6,12,8$, and 9 attempts in 2013, 2014, 2015 and 2016, respectively). We found that the level of nest-site defence aggression is independent of the probabilities of pairing and depredation (analysed on our long-term dataset covering 14 study years (2003-2016) and 295 individual males; Szász et al. 2019). Therefore, our video recorded sample of the assayed males should be representative of the natural range of attack latency in our study population. In our analyses, we did not consider the breeding attempt of those assayed males that bred outside of our core study site experiencing very different phenology (1 case), bred exceptionally late in the season when usually only replacement attempts occur (3 cases), were accidentally involved in an experiment because resighting was unsuccessful (2 cases) or were polygynous (2 cases). 
Altogether, we had video recordings of the feeding activity of 42 assayed males and their breeding partners for the statistical analyses. Before the video recording, nests of the assayed males were undisturbed by trapping and measuring, and they were only checked to find out the date and success of hatching. We video recorded the feeding activity of the assayed males when the nestlings were 9-11 days old. The number of nestlings at recording ranged from 4 to 7 (mean $\pm \mathrm{SE}=5.7$ \pm 0.8 ). We started all records in the morning (video start time 7:26-9:13 a.m.) when feeding activity of birds peaks. The cameras were hidden in the vegetation roughly $20-30 \mathrm{~m}$ from the focal nest-box. Setting up and presence of the camera did not seem to cause lasting stress for the parents as they always returned to feed their nestlings within 2-3 min (mean $\pm \mathrm{SE}=$ males: $171.6 \pm 139.5 \mathrm{~s}$; females: $146.0 \pm 127.7 \mathrm{~s})$. Moreover, some parents even continued feeding while we handled the camera. We intended to record at least $2 \mathrm{~h}$ of feeding (video length mean $\pm \mathrm{SE}=133 \pm 21 \mathrm{~min}$ ). Unfortunately, because of sudden rainstorms, we had to interrupt two of the videos resulting in shorter records (68 and $92 \mathrm{~min}$ ). The inclusion of these shorter videos did not change the results qualitatively (results not shown), so we present the results for the larger dataset. After the video recording, we caught the parents in their nest-box with traditional spring taps, and measured their tarsus length, body mass, WPS and FPS in the same way as described above. Females cannot be reliably assigned to age categories based on plumage characteristics, so we determined their minimum age based on ringing history. Female parents ringed as nestlings in the previous year and ringed as adult in the respective year were assigned as first-year; otherwise, they were assigned as older. In seven cases, we failed to resight the assayed males before the standard handling procedures so their identity was only found out in hand and therefore, the video recording was done 1 or 2 days after the measurements from both parents were taken. The inclusion of these parents did not change the results qualitatively (results not shown), so we present the results for the complete dataset.

All videos were processed by the same person (ES) following a blinded protocol i.e. without knowledge on the morphology of individuals and their exact performance during the prior behavioural assays. The videos were watched at natural speed. Starting and ending time of all events when an individual was present were noted for the male and the female parent separately. Feeding events were considered to occur when the parents carried food item, and either gave it in from the entrance hole or brought it into the nest-box. When calculating feeding variables, we subtracted the time elapsed between the start of the video and the first feeding event of the individual (for the male and the female parent separately) from the whole length of the record, and calculated the number of feeding events without the first one. In case of disturbances involving the occurrence of a potential predator (either a co-worker $(2$ cases) or a woodpecker (6 cases)), video length and number of feeding events were also corrected by the duration of the disturbance and the first feeding event after the disturbance, respectively. Feeding rate was the corrected number of feeding events per hour and per nestling. Thereby, feeding rate was controlled for (1) individual differences in risk-avoidance, (2) video length and (3) differences in brood size.

\section{Statistical analyses}

We analysed the possible association between male aggression and nestling feeding activity in R statistical environment (version 3.1.1; R Core Team 2014) building GLM with Gaussian error (using the function "lm" of the package "Ime4"; Bates et al. 2015).

The response variable was the feeding rate of males per hour per nestling. The focal explanatory variable was the attack latency of males that was $\log 10(x+1)$-transformed to improve its distribution. We also considered the following explanatory variables. Year and calendar date of the video record compared to the yearly median calendar date of broods of 10-day-old nestlings in the study population (the mean \pm SE age of the video recorded, analysed broods was $10.1 \pm$ 0.3 days). This relative date was highly correlated with relative laying date (calendar date of the first egg; $r=0.847$, $p<0.001$ ). Binary age (first-year or older), tarsus length, body condition, WPS of each parent, FPS of the male parent and feeding rate (per hour per nestling) of the female parent were also included in the full model. Body condition was the residual of body mass/tarsus length regression in the years, and the sexes separately based on character values of the whole population. Attack latency, tarsus length, WPS and FPS were centered to the yearly mean values of the population in the sexes separately. In case of attack latency and WPS of males, centering was conducted in the age categories separately because first-year males are more aggressive during territorial challenge and bear smaller wing patches than older males (Török et al. 2003; Garamszegi et al. 2006). There was no confounding multicollinearity between the explanatory variables (all variance inflation factors $<1.454$; Graham 2003; function "vif" of package "car"; Fox and Weisberg 2011). Because feeding rate was calculated per hour per nestling (see above), brood size was not considered in the models. Age of the nestlings and starting time of the video were also disregarded because they were standard across all nests (see above).

We applied backward stepwise elimination of nonsignificant terms (with a threshold of $p>0.05$ ) to find the model best fitting the variation in male feeding activity. Then, the removed explanatory variables were added oneby-one to the final model to yield reliable parameter estimates (Hegyi and Laczi 2015). We present Type III Wald F tests. Applying information criterion-based model selection to find 
the best-fitting model yielded similar results (see Electronic supplementary material for the details).

\section{Results}

In our dataset, male collared flycatchers averaged $4.6 \pm 1.3$ (mean $\pm \mathrm{SE}$ ) feeding events per hour per nestling, and their breeding partners averaged the same (mean $\pm \mathrm{SE}=4.6 \pm$ 1.3). Feeding rates of the parents did not significantly correlate with each other $(r=0.212, p=0.178, n=42)$.

Aggression during nest-site defence did not explain variance in male feeding rate. Furthermore, from the considered explanatory variables, only the year had a significant effect on male feeding rate, while all the other explanatory variables dropped out during the backward stepwise elimination procedure. Likewise, all explanatory variables turned out to be nonsignificant when tested in the final model (Table 1).

\section{Discussion}

In a wild population of collared flycatchers, we examined whether the territorial performance of males during the courtship period could carry information about the amount of parental care they will provide. Earlier, we found that sex allocation was related to male nest-site defence aggression with female-biased offspring sex ratio in broods attended by more aggressive fathers and male-biased offspring sex ratio in broods attended by less aggressive fathers (Szász et al. 2014). Given that males are more sensitive to the quality of the rearing environment than females both in terms of nestling development (Rosivall et al. 2010) and lifetime reproductive success (Szász et al. 2017), we hypothesised that the observed sex allocation could be explained by a negative link between aggression and provisioning of the father. However, we did not find such a link as more and less aggressive fathers cared similarly for their nestlings. Though we cannot fully exclude the possibility that the relationship between aggression and provisioning is very weak and could not been detected because of the moderate sample size, there are several possible biological explanations for the lack of the hypothesised link.

The finding that more and less aggressive males provide a similar amount of parental care is in agreement with our longterm study on the fitness consequences of nest-site defence aggression (Szász et al. 2019). More and less aggressive males fledged a similar number of offspring, which recruited to the population with a similar probability (Szász et al. 2019). Together, our results suggest that in our study population, regarding reproductive success, there is no selective advantage of being either more or less aggressive in the context of nest-site competition. Some other studies also suggest that nestling feeding activity or net reproductive success could be similar across different behavioural phenotypes. For example, though problem-solver and non-solver great tit (Parus major) females differed in the spatial and temporal efficiency of foraging, their feeding rate and time spent on feeding did not differ (Cole et al. 2012). Furthermore, though problemsolvers laid larger clutches, they abandoned their nest between hatching and fledging more often than non-solvers resulting in no selective difference among them (Cole et al. 2012). Another study showed that chestnut thrush (Turdus rubrocanus) females preferred different nest-sites according to their level of stress tolerance, and those nest-sites had contrasting effects on nestling number and mass indicating no difference in net reproductive benefit of bold and shy mothers (Zhao et al. 2016). Lastly, though more aggressive blue tit (Cyanistes caeruleus) males fed their nestlings at a lower rate, they elicited compensation from their breeding partners, so their reproductive success was not lower than that of less aggressive males (Mutzel et al. 2013).

It is also possible that expression of behavioural traits is considerably influenced by individual state and environmental quality, and the integration of behaviour does not carry over from one period to another. The study on western bluebirds (Sialia mexicana, Duckworth 2006) and blue tits (Mutzel et al. 2013) that found a negative relationship between male aggression and provisioning measured both behaviours on the same territory and in the same or close (respectively) time periods. In contrast, because we addressed the role of aggression in mate choice, we compared courtship behaviour with parental behaviour a month later (mean $\pm \mathrm{SE}=31.8 \pm 12.1$ days), and about half of the males $(n=20)$ eventually bred in another territory than its courtship territory, which could be responsible for the lack of the relationship. Some recent results in our study population support this idea. Escape ability of collared flycatcher males (a behavioural trait that was individualspecific within a period) declined from courtship to parental care, and the magnitude of the decline was partly explained by a change in their body condition (Jablonszky et al. 2017). Furthermore, consistency of song characteristics of males declined with change of nest-box and progress in time (Zsebök et al. 2017). However, male feeding rate was not explained by the interactive effect of latency to attack and change of nest-box (GLM with year as fixed factor: $F_{(1}$, $35)=1.059, p=0.766$ ) or the interactive effect of latency to attack and time elapsed between the behavioural assay and the feeding observation (GLM with year as fixed factor: $\left.F_{(1,35)}=0.091, p=0.310\right)$.

An alternative explanation for why we did not find a relationship between aggression and parental care relies on the seasonality of testosterone profile in migratory, monogamous passerines. Testosterone level is high during territory establishment and the fertile period of the social mate, and low during nestling care (Wingfield et al. 1987). This pattern is known to be advantageous, because in many species, 
Table 1 Feeding rate (calculated per hour per nestling) of male collared flycatchers in relation to their level of nest-site defence aggression, their morphology and the morphology of their breeding partners ( $n=42$ broods)

\begin{tabular}{llll}
\hline Explanatory variables & Estimate $\pm \mathrm{SE}$ & $F(\mathrm{df})$ & $p$ \\
\hline Year (reference 2013) & & $4.107(3,38)$ & 0.013 \\
2014 & $-1.011 \pm 0.708$ & & \\
2015 & $0.413 \pm 0.646$ & & \\
2016 & $-0.864 \pm 0.624$ & $0.294(1,37)$ & 0.591 \\
Date & $0.029 \pm 0.054$ & $0.531(1,37)$ & 0.471 \\
Attack latency & $-0.169 \pm 0.232$ & $1.489(1,37)$ & 0.230 \\
Age (reference subadult) & & & \\
$\quad$ Adult & $-0.473 \pm 0.388$ & $0.024(1,37)$ & 0.877 \\
Tarsus length & $-0.007 \pm 0.047$ & $0.101(1,37)$ & 0.752 \\
Body condition & $0.009 \pm 0.029$ & $0.016(1,37)$ & 0.899 \\
Wing patch size & $3.6 \mathrm{e}-04 \pm 0.003$ & $0.066(1,37)$ & 0.799 \\
Forehead patch size & $-3.1 \mathrm{e}-05 \pm 1.2 \mathrm{e}-04$ & $0.506(1,37)$ & 0.481 \\
Partner age (reference subadult) & & & \\
$\quad$ Adult & $-0.253 \pm 0.356$ & $0.893(1,37)$ & 0.351 \\
Partner tarsus length & $-0.034 \pm 0.036$ & $0.069(1,37)$ & 0.794 \\
Partner body condition & $0.008 \pm 0.032$ & $0.106(1,37)$ & 0.746 \\
Partner wing patch size & $8.1 \mathrm{e}-04 \pm 0.002$ & $0.699(1,37)$ & 0.409 \\
Partner feeding rate & $0.121 \pm 0.145$ & &
\end{tabular}

Significant effects retained in the final model are highlighted in italics

$F$ and $p$ values for non-significant terms are derived from the model containing the term in question and year (the only variable retained in the final model)

Year was a categorical variable with four levels (2013-2016)

Date was the calendar date of the feeding video relative to the median calendar date of broods of 10-day-old nestlings

Age was a categorical variable with two levels: first-year (individuals in their first breeding season) and older Body condition was the residual of body mass/tarsus length regression for years and sexes separately

Tarsus length, WPS and FPS were centered to the yearly mean values and in case of males, attack latency and WPS were centered in the age categories separately

$W P S$, wing patch size; FPS, forehead patch size experimentally prolonged high testosterone level encouraged territorial and courtship behaviours, while suppressed parental behaviours (Silverin 1980; Wingfield 1985; Hegner and Wingfield 1987; Ketterson et al. 1992). Under natural conditions, however, the drop in testosterone level from mating to parenting could be associated with a decline in the amongindividual variance in testosterone levels (Kempenaers et al. 2008). We are not aware of any study specifically addressing this issue, but there is indication in the literature that this assumption may be right. In an experimental study in blue tits, the mean testosterone level of control males was six times lower during nestling feeding than nest building, and in parallel, the range of testosterone levels was two times lower (Foerster and Kempenaers 2004). Similarly, in black redstart (Phoenicurus ochruros) males, the mean of pre-treatment testosterone level was five times lower, and the range of pretreatment testosterone levels was three times lower during nestling feeding than mate guarding (Villavicencio et al. 2014; C.P. Villavicencio pers. commun.). Most importantly, in the closely related pied flycatcher (Ficedula hypoleuca), in control males, the mean testosterone level was seven or 11 times lower during nestling feeding than before nest building depending on whether the male was unpaired or already paired when the first hormone measurement was taken, and the range of testosterone levels was four times lower (Silverin 1993). Moreover, after a simulated territorial intrusion, attacking pied flycatcher males had significantly higher testosterone levels than non-attacking pied flycatcher males before nest building, while there was no difference in the testosterone levels of attacking and non-attacking males when the intrusions were conducted in the nestling feeding period (Silverin 1993). Accordingly, differences in aggression among males during courtship may not manifest in correlated amongindividual differences in nestling feeding.

The lack of the expected relationship between nest-site defence aggression and nestling provisioning does not necessarily exclude the possibility that territorial performance is under surveillance during mate choice. It is possible that females choose males with similar or complementary behavioural type, with whom they could provide more efficient parental 
care. In passerines exhibiting biparental care, successful breeding has shown to be influenced by the behavioural compatibility of the breeding partners (Both et al. 2005; Spoon et al. 2006; Schuett et al. 2011). Accordingly, nestling feeding activity and, in turn, reproductive success across pairs of different behavioural composition could be comparable due to effective behavioural coordination within the pairs. However, feeding activity of the breeding partners was not related to each other significantly; therefore, this possibility is not very likely in our case.

Besides territorial behaviour, the morphological traits of males or those of their breeding partners did not predict male nestling provisioning either. This is not surprising regarding that two earlier, experimental studies on parental care in our study population yielded similar results for the traits used in the present study (Kiss et al. 2013; Laczi et al. 2017). The first study was a full cross-fostering experiment and revealed a positive effect of WPS of the genetic mother on the feeding rate of both foster parents (Kiss et al. 2013). Phenotypic traits of the foster mother and father were not related to their feeding rate (Kiss et al. 2013). Therefore, it suggested that offspring innate quality rather than parental morphology determines feeding activity. Nestlings of large-patched mothers may have behaved more demandingly or conspicuously in foster nests, or may have elicited greater investment from their foster parents. The second study conducted brood size manipulation and found no effect of the patch sizes of either parent on nestling provisioning in any of the treatment groups (Laczi et al. 2017).

To summarise, aggressive performance of collared flycatcher males during territorial challenge in the courtship period does not seem to predict their future parental investment in nestling feeding. This result leaves open the question of why females apparently adjust the sex ratio of their brood to the nest-site defence aggression of their mates. More generally, future studies on other species and other behavioural traits are warranted to explore whether behavioural performances that are witnessed by females during mate choice may be indicators of future parental commitment and thereby adaptively modify female reproductive decisions.

Acknowledgements We thank Mónika Jablonszky, Dóra Kötél, Katalin Krenhardt, Miklós Laczi, Gergely Nagy and Sándor Zsebők for their help in the field. We are thankful to the Erdők a Közjóért Alapítvány and the Pilis Park Forestry for their support. We thank Kees van Oers and two anonymous reviewers for their comments on our manuscript.

Funding Open access funding provided by Eötvös Loránd University (ELTE). The study was funded by the following grants: PhD scholarship to ES from the Doctoral School of Biology, Eötvös Loránd University, Hungary; scholarship to ES (grant no. ÚNKP-16-3-ELTE-8495/6/2016) from the New National Excellence Program of the Ministry of Human Capacities, Hungary; scholarship to GM (grant no. 20430-3/2018/ FEKUTSTRAT) from the Higher Education Institutional Excellence Program of the Ministry of Human Capacities, Hungary; János Bolyai research scholarship to BR from the Hungarian Academy of Sciences; NKFIH research grants to JT (grant no. K1159709), BR (grant no. K120249), GH (grant no. K124443) and LZG (grant no. K129215) from the Hungarian National Research, Development and Innovation Office and research grant to LZG from the Ministry of Economy and Competitiveness, Spain (grant no. CGL2015-70639-P).

\section{Compliance with ethical standards}

Conflict of interest The authors declare that they have no conflict of interest.

Ethical approval The study was evaluated and received prior approval by the Department of Environment and Nature Protection of the Hungarian Government Office (case no. KTVF/10949-8/2013, PE/ $\mathrm{KTF} / 11978-5 / 2015$, PE/KTF/11978-6/2015) and meets the ASAB/ABS guidelines for the use of animals in research. All authors are licenced to handle and test animals by the Committee on Animal Welfare of the Eötvös Loránd University.

Open Access This article is distributed under the terms of the Creative Commons Attribution 4.0 International License (http:// creativecommons.org/licenses/by/4.0/), which permits unrestricted use, distribution, and reproduction in any medium, provided you give appropriate credit to the original author(s) and the source, provide a link to the Creative Commons license, and indicate if changes were made.

\section{References}

Bakker TCM (1986) Aggressiveness in sticklebacks (Gasterosteus aculeatus L.): a behaviour-genetic study. Behaviour 98:1-144

Bates D, Maechler M, Bolker B, Walker S (2015) Fitting linear mixedeffects models using lme4. J Stat Softw 67:1-48

Both C, Dingemanse NJ, Drent PJ, Tinbergen J (2005) Pairs of extreme avian personalities have highest reproductive success. J Anim Ecol 74:667-674

Carere C, Groothuis TGG, Mostl E, Daan S, Koolhaas JM (2003) Fecal corticosteroids in a territorial bird selected for different personalities: daily rhythm and the response to social stress. Horm Behav 43:540 548

Cole EF, Morand-Ferron J, Hinks AE, Quinn JL (2012) Cognitive ability influences reproductive life history variation in the wild. Curr Biol 22:1808-1812

Cramp S, Perrins CM (1993) The birds of the Western Palearctic, VII. Flycatchers to shrikes. Oxford University Press, Oxford

Dolby AS, Clarkson CE, Haas ET, Miller JK, Havens LE, Cox BK (2005) Do song-phrase production rate and song versatility honestly communicate male parental quality in the Gray Catbird? J Field Ornithol 76:287-292

Duckworth RA (2006) Behavioral correlations across breeding contexts provide a mechanism for a cost of aggression. Behav Ecol 17:10111019

Foerster K, Kempenaers B (2004) Experimentally elevated plasma levels of testosterone do not increase male reproductive success in blue tits. Behav Ecol Sociobiol 56:482-490

Foster SA, Baker JA, Bell MA (1992) Phenotypic integration of life history and morphology: an example from three-spined stickleback, Gasterosteus aculeatus L. J Fish Biol 41:21-35

Fox J, Weisberg S (2011) An $\{\mathrm{R}\}$ companion to applied regression, 2nd edn. Sage, Thousand Oaks http://socserv.socsci.mcmaster.ca/jfox/ Books/Companion 
Garamszegi L, Møller AP, Török J, Michl G, Péczely P, Richard M (2004) Immune challenge mediates vocal communication in a passerine bird: an experiment. Behav Ecol 15:148-157

Garamszegi LZ, Rosivall B, Hegyi G, Szöllősi E, Török J, Eens M (2006) Determinants of male territorial behavior in a Hungarian collared flycatcher population: plumage traits of residents and challengers. Behav Ecol Sociobiol 60:663-671

Garamszegi LZ, Markó G, Szász E, Zsebők S, Azcárate M, Herczeg G, Török J (2015) Among-year variation in the repeatability, withinand between-individual, and phenotypic correlations of behaviors in a natural population. Behav Ecol Sociobiol 69:2005-2017

Graham MH (2003) Confronting multicollinearity in ecological multiple regression. Ecology 84:2809-2815

Grenna M, Avidano L, Malacarne G, Leboucher G, Cucco M (2014) Influence of male dominance on egg testosterone and antibacterial substances in the egg of grey partridges. Ethology 120:149-158

Gwinner H, Schwabl H (2005) Evidence for sexy son hypothesis in European starlings (Sturnus vulgaris). Behav Ecol Sociobiol 58: 375-382

Hegner RE, Wingfield JC (1987) Effects of experimental manipulation of testosterone levels on parental investment and breeding success in male house sparrows. Auk 104:462-469

Hegyi G, Laczi M (2015) Using full models, stepwise regression and model selection in ecological data sets: Monte Carlo simulations. Ann Zool Fenn 52:145-159

Hegyi G, Török J, Tóth L (2002) Qualitative population divergence in proximate determination of a sexually selected trait in the collared flycatcher. J Evol Biol 15:710-719

Hegyi G, Török J, Garamszegi LZ, Rosivall B, Szöllősi E, Hargitai R (2007) Dynamics of multiple sexual signals in relation to climatic conditions. Evol Ecol Res 9:905-920

Hegyi G, Kötél D, Laczi M (2015) Direct benefits of mate choice: a metaanalysis of plumage colour and offspring feeding rates in birds. Sci Nat 102:62

Hofstad E, Espmark Y, Moksnes A, Haugan T, Ingebrigtsen M (2002) The relationship between song performance and male quality in snow buntings (Plectrophenax nivalis). Can J Zool 80:524-531

Jablonszky M, Szász E, Markó G, Török J, Herczeg G, Garamszegi LZ (2017) Escape ability and risk-taking behaviour in a Hungarian population of the collared flycatcher (Ficedula albicollis). Behav Ecol Sociobiol 71:54

Kempenaers B, Peres A, Foerster K (2008) Sources of individual variation in plasma testosterone levels. Phil Trans R Soc B 363:17111723

Ketterson ED, Nolan V Jr, Wolf L, Ziegenfus C (1992) Testosterone and avian life histories: effects of experimentally elevated testosterone on behavior and correlates of fitness in the Dark-eyed Junco (Junco hyemalis). Am Nat 140:980-999

Kiss D, Hegyi G, Török J, Rosivall B (2013) The relationship between maternal ornamentation and feeding rate is explained by intrinsic nestling quality. Behav Ecol Sociobiol 67:185-192

Kralj-Fišer S, Scheiber IBR, Blejec A, Möstl E, Kotrschal K (2007) Individualities in a flock of free-roaming greylag geese: behavioral and physiological consistency over time and across situations. Horm Behav 51:239-248

Kunc HP, Amrhein V, Naguib M (2006) Vocal interactions in nightingales, Luscinia megarhynchos: more aggressive males have higher pairing success. Anim Behav 72:25-30

Laczi M, Kötél D, Török J, Hegyi G (2017) Mutual plumage ornamentation and biparental care: consequences for success in different environments. Behav Ecol 28:1359-1368

Michl G, Török J, Griffith SC, Shledon BC (2002) Experimental analysis of sperm competition mechanisms in a wild bird population. Proc Natl Acad Sci USA 99:5466-5470
Mutzel A, Dingemanse NJ, Araya-Ajoy YG, Kempenaers B (2013) Parental provisioning behaviour plays a key role in linking personality with reproductive success. Proc R Soc B 280:20131019

Ophir AG, Galef BG Jr (2003) Female Japanese quail that 'eavesdrop' on fighting males prefer losers to winners. Anim Behav 66:399-407

Ophir AG, Persaud KN, Galef BG Jr (2005) Avoidance of relatively aggressive male japanese quail (Coturnix japonica) by sexually experienced conspecific females. J Comp Psychol 119:3-7

Otter K, Ratcliffe L (1996) Female initiated divorce in a monogamous songbird: abandoning mates for males of higher quality. Proc R Soc Lond B 263:351-355

R Core Team (2014) R: A language and environment for statistical computing. R Foundation for Statistical Computing, Vienna http://www. R-project.org/

Ramsay SM, Mennill DJ, Otter KA, Ratcliffe LM, Boag PT (2003) Sex allocation in black-capped chickadees Poecile atricapilla. J Avian Biol 34:134-139

Réale D, Garant D, Humphries MM, Bergeron P, Careau V, Montiglio PO (2010) Personality and the emergence of the pace-of-life syndrome concept at the population level. Phil Trans R Soc B 365:4051-4063

Ricklefs RE, Wikelski M (2002) The physiology/lifehistory nexus. Trends Ecol Evol 17:462-468

Rinden H, Lampe HM, Slagsvold T, Espmark YO (2000) Song quality does not indicate male parental abilities in the pied flycatcher Ficedula hypoleuca. Behaviour 137:809-823

Rosivall B, Szöllősi E, Hasselquist D, Török J (2010) Males are sensitive - sex-dependent effect of rearing conditions on nestling growth. Behav Ecol Sociobiol 64(10):1555-1562

Schuett W, Dall SRX, Royle NJ (2011) Pairs of zebra finches with similar 'personalities' make better parents. Anim Behav 81:609-618

Sih A, Bell A, Johnson JC (2004) Behavioral syndromes: an ecological and evolutionary overview. Trends Ecol Evol 19:372-378

Silver R, Andrews H, Ball GF (1985) Parental care in an ecological perspective: a quantitative analysis of avian subfamilies. Am Zool $25: 823-840$

Silverin B (1980) Effects of long-acting testosterone treatment on freeliving pied flycatchers, Ficedula hypoleuca, during the breeding period. Anim Behav 28:906-912

Silverin B (1993) Territorial aggressiveness and its relation to the endocrine system in the pied flycatcher. Gen Comp Endocrinol 89:206213

Spoon TR, Millam JR, Owings DH (2006) The importance of mate behavioural compatibility in parenting and reproductive success by cockatiels, Nymphicus hollandicus. Anim Behav 71:315-326

Stearns SC (1976) Life history tactics: a review of the ideas. Q Rev Biol $51: 3-47$

Stearns SC (1989) Trade-offs in life-history evolution. Funct Ecol 3:259268

Svensson L (1992) Identification guide to European passerines. British Trust for Ornithology, Stockholm

Szász E, Garamszegi LZ, Hegyi G, Szöllősi E, Markó G, Török J, Rosivall B (2014) Aggressive behavior of the male parent predicts brood sex ratio in a songbird. Naturwissenschaften 101:653-660

Szász E, Szöllősi E, Hegyi G, Török J, Rosivall B (2017) Rearing conditions have long-term sex-specific fitness consequences in the collared flycatcher. Behav Ecol 28:717-723

Szász E, Jablonszky M, Krenhardt K et al (2019) Male territorial aggression and fitness in collared flycatchers: a long-term study. Sci Nat 106:11

Török J, Hegyi G, Garamszegi LZ (2003) Depigmented wing patch size is a condition-dependent indicator of viability in male collared flycatchers. Behav Ecol 14:382-388

van Oers K, de Jong G, Drent PJ, van Noordwijk AJ (2004) A genetic analysis of avian personality traits: correlated response to artificial selection. Behav Genet 34:611-619 
Villavicencio CP, Apfelbeck B, Goymann W (2014) Parental care, loss of paternity and circulating levels of testosterone and corticosterone in a socially monogamous song bird. Front Zool 11:11

Williams GC (1966) Natural selection, the costs of reproduction, and a refinement of Lack's principle. Am Nat 100:687-692

Wingfield JC (1985) Short-term changes in plasma levels of hormones during establishment and defence of a breeding territory in male song sparrows, Melospiza melodia. Horm Behav 19:174-187

Wingfield JC, Ball GF, Dufty AM, Hegner RE, Ramenofsky M (1987) Testosterone and aggression in birds. Am Sci 75:602-608
Zhao QS, Hu YB, Liu PF, Chen LJ, Sun YH (2016) Nest site choice: a potential pathway linking personality and reproductive success. Anim Behav 118:97-103

Zsebők S, Herczeg G, Gy B, Laczi M, Nagy G, Szász E, Markó G, Török J, Garamszegi LZ (2017) Short- and long-term repeatability and pseudo-repeatability of bird song: sensitivity of signals to varying environments. Behav Ecol Sociobiol 71:154

Publisher's note Springer Nature remains neutral with regard to jurisdictional claims in published maps and institutional affiliations.

\section{Affiliations}

\section{Eszter Szász ${ }^{1}$ (D) • Gábor Markó ${ }^{1,2} \cdot$ Gergely Hegyi $^{1}$ · János Török ${ }^{1}$ • László Zsolt Garamszegi ${ }^{3,4,5}$ • Balázs Rosivall ${ }^{1}$}

1 Behavioural Ecology Group, Department of Systematic Zoology and Ecology, Eötvös Loránd University, Pázmány Péter sétány 1/C, Budapest 1117, Hungary

2 Department of Plant Pathology, Szent István University, Villányi út 29-43, Budapest 1118, Hungary

3 Departamento de Ecología Evolutiva, Estación Biológica de Donaña-CSIC, C/Americo Vespucio, 26, 41092 Seville, Spain
4 MTA-ELTE Theoretical Biology and Evolutionary Ecology Research Group, Eötvös Loránd University, Pázmány Péter sétány 1/C, Budapest 1117, Hungary

5 Institute of Ecology and Botany, Centre for Ecological Research, Hungarian Academy of Sciences, Alkotmány utca 2-4, Vácrátót 2163, Hungary 